\title{
Forecasting Weekly Auction of the 91-Day Treasury Bill Rates of Ghana
}

\author{
Francis Okyere $^{1}$, Salifu Nanga ${ }^{2}$ \\ ${ }^{1,2}$ (Department of Statistics, School of Graduate Studies, University of Ghana, P. O. Box LG 571, Legon, Accra, \\ Ghana) \\ I'National Vocational Training Institute (NVTI), P. O. Box MB 21, Accra, Ghana) \\ ${ }_{2}^{2}$ Wisconsin International University College, Ghana)
}

\begin{abstract}
A Treasury Bill is a short term investment product offered by the Bank of Ghana on behalf of the government. An investor in Treasury Bills lends his/her idle funds to the government at a fixed interest rate for either 91, 182 or 364 days. In this study we employed univariate time series Autoregressive Integrated Moving Average (ARIMA) model to forecast government 91-Day Treasury Bill rates for the next eighteen (18) weeks in Ghana in 2014 using Box Jenkins approach. The results showed that ARIMA $(2,0,1)$ model was appropriate for modelling the weekly auction of 91-Day Treasury Bill rates with a maximum log likelihood value of 246.42, and least AIC value of -482.83, AICc value of -482.14 and BIC value of -470.23. An ARCH-LM test and Ljung-Box test on the residuals of the models revealed that the residuals are free from heteroscedasticity and serial correlation respectively. Therefore investors can plan their future investments by considering the future behavior of the 91-Day Treasury Bill rates for next eighteen (18) weeks.
\end{abstract}

Keywords: ARIMA model, Bank of Ghana, Box Jenkins, Forecasting, Treasury Bill rates

\section{Introduction}

Almost all individuals have wealth of some kind, ranging from the value of their services in the workplace, tangible assets to monetary assets and there is a reward expectation to minimize or avoid risk like the Treasury Bill product offered by Bank of Ghana. It is unsafe to keep money at home or buried not only because of the risk of loss through theft or natural disasters, but because the value of the money depreciates especially in the economy of a developing country like Ghana where inflation rate keep rising by the day. Besides that, even in a deposit account where the interest is far below inflation rate, you will lose some percentage in a year if you leave the money in deposit account. Money may be kept in the bank or loaned to the government through the purchase of Treasury Bills. This would afford a high degree of safety. Investors objectives may vary and relative, aside hedging against inflation, one may invest for growth, income and security [1].

For most of your life, you will be earning and spending money. Rarely, though will your current income exactly balance with your consumption desires. Sometimes, you may have more money than you want to spend; at other times, you may want to purchase more than you benefit from your income [6]. One would therefore need to invest to meet some known or unforeseen circumstances in the future.

In general, investors do not like rising prices because that introduces uncertainty into their lives and makes it difficult to plan for the future. Therefore, investors focus on the returns they will receive over and above the rate of inflation [6].

Treasury bill is a short-term investment product offered by the Bank of Ghana on behalf of the government. They are backed by the Ghana Government Guarantee. An investor in Treasury bills lends his/her idle funds to the government at a fixed interest rate for either 91, 182 or 364 days. When the bill matures, that is at the end of the specific period, the government will repay the principal (the amount it borrowed) plus the specific or agreed interest rate at the time of the purchase. The interest rate payable however depends on the length of the period [1].

You may purchase treasury bills through a licensed Bank of Ghana Primary Distributor and the investor pays nothing as transaction cost. One may choose to take your interest/discount up front or may take it together with the entire principal at the maturity date [1].

On the other hand, investment in treasury bills is risk free. The rate of return on treasury bills can be estimated quite precisely. That is, you are sure of exactly how much you will earn upon the maturity of the investment. Theory thus has it that no investment should be undertaken unless the expected return is high enough to compensate the investor for the perceived risk of investment. The high the probability of default, the riskier the investment; and the higher the risk, the higher the required rate of return [1].

In spite of these higher returns, it appears more Ghanaians are so impressed with an observable high rate of returns on treasury bills, especially comparing the performance of 91-Day Treasury bill rates to 182 and 364 Day Treasury bill rates. 
Finance theory on the other hand, has it that the rate of return an investor earns is dependent on the level of risk involved in that investment. Risk refers to the chance that some inauspicious event will occur [4]. Jacoby et al provided theoretical arguments to show how treasury bills impacts stock market prices [7]. Jones showed that stock prices predicted expected returns in the time-series [2]. As more data has become available, recent work has shifted focus on studying time-series properties of risk in equity markets as well as in Treasury bills. Huang et al related risk to return volatility [18], while Brandt studied the relationship between liquidity, order flow and the yield curve [14].

Literature seems to suggest that stocks provide higher returns than other investments. Common stock has provided the highest rate of return to investors in the United States [6]. A study by R. G. Ibbotson \& Associates found that, over the period 1926-96, large company common stock provided an arithmetic average annual return of 12.7 percent in USA. This compares with an average annual return of 6 percent for long-term corporate bonds, and 3.8 percent for U.S. Treasury bills [17]. Aboagye in studying the performance of stocks in Ghana, found out that investors in stock exchange traded shares earned on average $54 \%$ per annum, whereas Treasury bill investors earned $36.3 \%$ [16].

Empirical researches have been carried out in the area of forecasting using Autoregressive Integrated Moving Average (ARIMA) models popularised by Box and Jenkins (1976). Paul et al used ARIMA model for forecasting average daily share price index of pharmaceutical companies in Bangladesh. In their study, they found the best fitted ARIMA model after considering the different type of factors such as Akaike Information, corrected Akaike information, Schwartz information, mean absolute percent error, root mean square error and absolute mean error. Their empirical results indicated that the ARIMA $(2,1,2)$ model is the best for forecasting the average daily share price indices [10].

Seneviratna and Shuhua, also used univariate time series Autoregressive Integrated Moving Average (ARIMA) model was used to forecast government twelve month Treasury bill rates in Sri Lanka over the period June, 2008 to June, 2013. Box Jenkins methodology was mainly used to build four models and different diagnostic tests and criteria were applied to select the appropriate model. The accuracy of the forecasted values was compared with Mean Squared Error (MSE) and Mean Absolute Error (MAE) and their results revealed that the best ARIMA model for the twelve month treasury bill rates is ARIMA $(1,1,2)[3]$.

Chujai et al conducted a research to find a model for forecasting the electricity consumption in a household. As a main objective of their study, the most suitable forecasting method was fitted. The analysis results suggested that, two forecasting methods called autoregressive integrated moving average and autoregressive moving average (ARMA) are most suitable for forecasting future results. For this purpose they applied Box Jenkins method and identified the best suitable model is ARIMA for monthly and quarterly as forecasting periods. On the other hand, they showed that the ARMA model is suitable for forecasting based on daily and weekly periods [15].

Inflation rate in Nigeria was forecasted by Olajide et al based on the Box Jenkins approach. Yearly data from 1961 to 2010 was used. According to the empirical results, they suggested that the ARIMA $(1,1,1)$ model is the most adequate for the inflation rate. Based on the suggested model, they predicted the inflation rate at $16.27 \%$ in the year 2010 [11].

Okyere and Mensah forecasted inflation rates of Ghana for 2014 base on the Box Jenkins approach. Monthly data from January 2009 to December 2013 was used. According to the results, they suggested that ARIMA $(1,2,1)$ model was appropriate for modelling the inflation rates with a maximum log likelihood value of -64.21, and least AIC value of 13.43, AICc value of 134.87 and BIC value of 140. 61. An ARCH-LM test and Ljung-Box test on theresiduals of the models revealed that the residuals are free from heteroscedasticity and serial correlation respectively. Ghana is likely to experience a persistence increase in inflation rate with double digit hence the government should reconsider his monetary policies [5].

Al-Sahib studied the predictability of the Amman Stock Exchange(ASE) based on ARIMA model over a period of seven days. Different diagnostic tests used to perform the best fitted model and showed that the selected model is suitable for forecasting on ASE [13]. Another research based on ARIMA model has done by Nochai et al. They investigated to find a model to forecast three types of oil palm price in Thailand such as Farm price, Wholesale price and Pure oil price. Non-seasonal Box Jenkins methodology is used and three models are found based on the minimum of mean absolute percentage error (MAPE). Finally they developed model for three types of palm oil price and found that models ARIMA $(2,1,0)$ for the farm price, ARIMA $(1,0,1)$ for the wholesale price, and ARIMA (3,0,0) for the pure oil price [19].

Again, Appiah and Adetunde used the Box and Jenkins (1976) approach to model and forecast the exchange rate between the Ghana cedi and the US dollar. In their study, they found that ARIMA $(1,1,1)$ model was appropriate for forecasting, the exchange rate [21].

Logubayom et al presented a study to build a univariate time series models to model the monthly Treasury bill rate of two short term Treasury bills (91 day and 182 day) from the year 1998 to 2012 from the Bank of Ghana using ARIMA models. From the results, it was realized that ARIMA $(3,1,1)$ model was 
appropriate for modelling the 91-day Treasury bill rate, ARIMA $(1,1,0)$ was the best model for the 182-day Treasury bill rates [8].

Finally, according to literature, another study was carried out by Nasiru and Sarpong employed an empirical approach in modelling and forecasting Inflation in Ghana using the Box-Jenkins approach. The result showed that ARIMA $(3,1,3)(2,1,1)[12]$ model was appropriate for modelling the inflation rates [20].

The main emphasis of investment is the future and gain. This means that if an investor is able to see a week or two (2) weeks ahead, concerning the 91-Day Treasury Bill, he/she will maximize his/her returns and also an investor whose maturity date is due will know when to roll-over.

In this study, our main objective was to model and forecast 91-Day Treasury bill rates for the next eighteen (18) weeks of Ghana outside the sample period. The post-sample forecasting is very important for investors of 91-Day Treasury bills for investment planning in future. That is for them to foresee ahead of time and to know when to purchase the Treasury bill especially 91-Day Treasury Bills and when to roll-over after the maturity date.

\section{Materials And Methods}

This study was carried out in Ghana in April, 2014, using weekly data on 91-Day Treasury bill rates from June 2011 to March 2014. The data was obtained from the website of the central Bank of Ghana. The data was modeled using Autoregressive Integrated Moving Average (ARIMA) stochastic model. An autoregressive integrated moving average (ARIMA) model is a generalization of an autoregressive moving average (ARMA) model. These models are fitted to time series data either to better understand the data or to predict future points in the series.

\subsection{Autoregressive Integrated Moving Average (ARIMA) Model}

A time series $Y_{t}$ is said to follow Autoregressive Integrated Moving Average (ARIMA) model if the $d$ th differences $\nabla^{d} Y_{t}$ follow a stationary ARMA model. There are three important values which characterize an ARIMA process [9]:

- $\quad p$, the order of the autoregressive component

- $d$, the number of differences needed to arrive at a stationary $\operatorname{ARMA}(p, q)$ process

- $q$, the order of the moving average component

The general form of the ARIMA $(p, d, q)$ is represented by a backward shift operator as

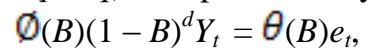

where the AR and MA characteristic operators are

$$
\begin{aligned}
& \emptyset_{(B)}=\left(1-\emptyset_{1} B-\emptyset_{1} B^{2}-\ldots-\emptyset_{p} B^{d}\right) \\
& \theta_{(B)}=\left(1-\theta_{1} B-\theta_{2} B^{2}-\ldots-\theta_{q} B^{q}\right)
\end{aligned}
$$

and

$$
(1-B)^{d} Y_{t}=\nabla^{d} Y_{t}
$$

where

$\emptyset$ is the parameter estimate of the Autogressive component

$\theta$ is the parameter estimate of the Moving Average component

$\nabla$ is the difference

$B$ is the Backward shift operator

$\mathrm{e}_{\mathrm{t}}$ is a purely a random process with mean zero and $\operatorname{var}\left(\mathrm{e}_{\mathrm{t}}\right)=\sigma_{\mathrm{e}}^{2}$

Estimating an ARIMA model was first approached by Box and Jenkins (1976) and according to their methodology, it follows three steps as Identification, Estimation, and Diagnostic Checking. The three steps can be summarized in the following below [9].

\subsection{Model Identification}

Identification step involves the use of the techniques to determine the values of $p, q$ and $d$. The values are determined by using Autocorrelation Function (ACF) and Partial Autocorrelation Function (PACF). For any ARIMA $(p, d, q)$ process, the theoretical PACF has non-zero partial autocorrelations at lags $1,2, \ldots, p$ and has zero partial autocorrelations at all lags, while the theoretical ACF has non zero autocorrelation at lags $1,2, \ldots, q$ and zero autocorrelations at all lags. The non-zero lags of the sample PACF and ACF are tentatively accepted as the $\mathrm{p}$ and $\mathrm{q}$ parameters. Bad choices of $p, d$, and $q$ lead to bad models, which, in turn, lead to bad predictions (forecasts) of future values [9]. 


\subsection{Unit Root Tests}

Determining whether the time series is stationary or not is a very important concept before making any inferences in time series analysis. Therefore Augmented Dickey Fuller (ADF) and Kwiatkowski-PhillipsSchmidt-Shin tests have been used to check the stationarity of the data series. The test is based on the assumption that a time series data $\mathrm{y}_{\mathrm{t}}$ follows a random walk [12]:

$$
\mathrm{Y}_{\mathrm{t}}=\rho \mathrm{y}_{\mathrm{t}-1}+\mathrm{e}_{\mathrm{t}}
$$

where $\rho$ is the characteristic root of an AR polynomial and $\mathrm{e}_{\mathrm{t}}$ is purely a random process with mean zero and variance $\sigma^{2}[9]$.

\subsubsection{Augmented Dickey Fuller (ADF) Test}

Dickey and Fuller (1979) ADF is a test to see if the test can reject non-stationarity. The ADF unit root test therefore tests [12],

$$
\mathrm{H}_{0}: \rho=1 \text { (non-stationary) }
$$

versus

$$
\mathrm{H}_{1}: \rho<1 \text { (stationary) }
$$

\subsubsection{Kwiatkowski Phillips Schmidt Shin (KPSS) Test}

Kwiatkowski et al (1992) KPSS is a test where the null hypothesis is the other way around. It is tests to see if the test can reject stationarity. This is the reverse of ADF test [12].

\subsection{Estimation of Model Parameters}

After identifying the possible ARIMA models, the maximum likelihood method is used to estimate the model parameters [9].

\subsection{Diagnostic Checking}

The next step is to select the best model among all the identified models. For this, residual diagnostics and the model with the maximum log-likelihood and minimum values of Akaike Information Criterion (AIC), modified Akaike Information Criterion (AICc), and Bayesian Information Criterion (BIC) was considered as the best model. Under the residual diagnostics, Ljung-Box Q statistic is used to check whether the residuals are random or not [9].

\subsubsection{Akaike Information Criterion (AIC)}

The Akaike's Information Criterion (AIC) says to select the $\operatorname{ARIMA}(p, d, q)$ model which minimizes

$$
\mathrm{AIC}=-2 \ln L+2 k \quad \text { (6) }
$$

where $\ln L$ is the natural logarithm of the estimated likelihood function and $k=p+q$ is the number of parameters in the model. The AIC is an estimator of the expected Kullback-Leibler divergence, which measures the closeness of a candidate model to the truth. The smaller this divergence, the better the model [9].

A problem arises in that $\mathrm{AIC}$ is a biased estimator of the expected $\operatorname{KL}$ divergence in $\operatorname{ARMA}(p, d, q)$ models. An alternative AIC statistic which corrects for this bias is [9],

\subsubsection{Bayesian Information Criterion (BIC)}

$$
\mathrm{AICC}=\mathrm{AIC}+\frac{2(K+1)(K+2)}{n-k-2}
$$

The Bayesian Information Criterion (BIC) says to select the $\operatorname{ARIMA}(p, d, q)$ model which minimizes [9],

$$
\mathrm{BIC}=-2 \ln L+2 k \ln (n)
$$

where $\ln L$ is the natural logarithm of the estimated likelihood function and $k=p+q$ is the number of parameters in the model and $n$ is total observations.

Both AIC and BIC require the maximization of the log likelihood function and When we compared AICC to BIC offers a stiffer penalty for overparameterized models [9].

An overall check of the model adequacy was made using the modified Box-Pierce $\boldsymbol{Q}$ statistics. The test statistics is given by:

$$
Q_{m}=n(n+2) \sum_{k=1}^{n}(n-k)^{-1} r_{k}^{2} \approx \chi_{m-r}^{2}
$$

where:

$$
\begin{aligned}
& r_{k}^{2}=\text { the residuals autocorrelation at lag } k \\
& n=\text { the number of residual } \\
& m=\text { the number of time lags included in the test. }
\end{aligned}
$$


When the $p$-value associated with the $Q$ is large the model is considered adequate, else the whole estimation process has to start again in order to get the most adequate model. Here all the tests were performed at the $95 \%$ confidence interval [9].

Furthermore, a plot of the ACF squared residual and PACF squared residuals was performed on the residuals of the fitted model to check for heteroscedasticity and again an ARCH LM-test for conformity of the presence of, or otherwise ARCH effect was performed.

\subsection{Forecasting}

Forecasting refers to the technique of predicting the future values $Y_{t+1}, Y_{t+2}, \ldots Y_{t+n}$. We refer to an arbitrary future value as $Y_{t+n}$, the value of the process at time $t+n$. In this context, we refer to $t$ as the forecast origin and $n$ as the lead time. The value $Y_{t+n}$ is $n$ steps ahead of the most recently observed value $Y_{t}$ [9]. Then the best fitted value has been used to forecast 91-Day Treasury bill rates for the next eighteen (18) weeks.

\subsection{Stationarity}

\section{Results And Discussion}

We stabilized non-variation in the original series of the 91-Treasury Bill rates by transforming it with the natural logarithm. After that a behavioral analysis was carried out on the time series plot and correlogram (ACF plot) and partial correlogram (PACF plot). The time series plot of fig.1 show the weekly 91-Day Treasury Bill rates of Ghana from June 2012 to March 2014 and it reveals an existence significant trend. The ACF plot of fig. 1 shows a sharp decay at lag 8 and this implies a stationarity in the transform data.
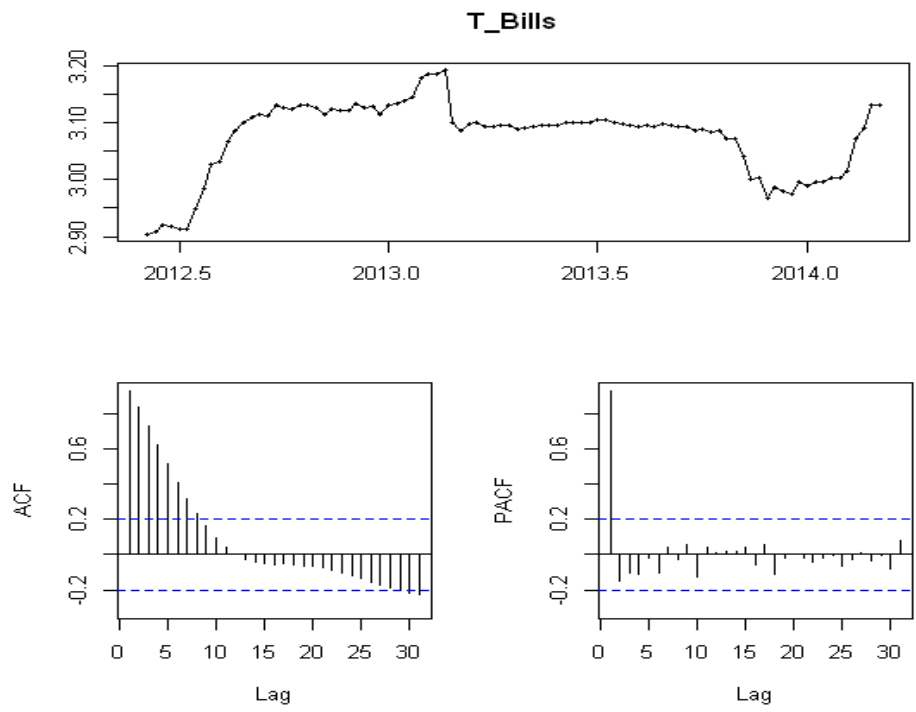

Figure 1: Time Series Plot and ACF and PACF plot

Table 1: Unit Root Tests Results

\begin{tabular}{|llll|} 
Tests & Order of Difference & Test Statistic & P-Value \\
ADF & 0 & -3.6853 & 0.03005 \\
\hline KPSS & 0 & 0.4562 & 0.05293 \\
\hline
\end{tabular}

The ADF and KPSS further confirm this affirmation that the data is stationary at the original level of the transform data. That is at $d=0$ the data is stationary. Remember that the KPSS test is a reverse of ADF [9].

\subsection{Model Identification}

From the results of fig. 1 and the unit root results, which revealed that the data is stationary at the original series, we can propose the moving average $(q)$ component and autogressive $(p)$ component with our zero (0) difference (ie. $d=0$ ) to form our ARIMA model based on the ACF and PACF plot in fig.1. The autocorrelation (ACF) plot in fig. 1 shows a spike from lag 1 to lag 8, indicating a moving average component need to be added to the model and Partial autocorrelation (PACF) plot in the same fig.1 shows a spike in lag 1, also indicating an autoregressive component need to be added to de model. 
Table 2: Different ARIMA $(p, 0, q)$ Model Fitted

\begin{tabular}{|lllll|}
\hline & AIC & AICC & BIC & $\begin{array}{l}\text { Log- } \\
\text { Likelihood }\end{array}$ \\
\hline ARIMA(1,0,1) & -474.78 & -474.32 & -464.69 & 241.39 \\
\hline ARIMA(1,0,2) & -478.52 & -477.82 & -465.91 & 244.26 \\
\hline ARIMA(1,0,3) & -478.95 & -477.96 & -463.82 & 245.48 \\
\hline ARIMA(1,0,4) & -476.98 & -475.64 & -459.32 & 245.49 \\
\hline ARIMA(1,0,5) & -476.60 & -474.87 & -456.43 & 246.30 \\
\hline ARIMA(1,0,6) & -474.61 & -472.41 & -451.91 & 246.30 \\
\hline ARIMA(1,0,7) & -473.36 & -470.64 & -448.14 & 246.68 \\
\hline ARIMA(1,0,8) & -471.44 & -468.14 & -443.70 & $246.72^{*}$ \\
\hline ARIMA(2,0,1) & $-482.83 *$ & $-482.14 *$ & $-470.23 *$ & 246.42 \\
\hline
\end{tabular}

*Best based on the model selection criterion

From Table 3, ARIMA $(2,0,1)$ was the best model based on the selection criterion used. This is because it satisfies most of the selection criterion. The parameters of this model were then estimated.

\subsection{Model Estimation}

Maximum likelihood is used to estimate the model parameters. As shown in Table 3 below show that with the exception of $\mathrm{AR}(1)$, the rest of the parameters were significant including the constant.

Table 3: Estimated model parameters

\begin{tabular}{|lllllll|}
\hline \multirow{3}{*}{ Model } & Component & Coefficient & S.E & Test Statistic & P-Value \\
\hline \multirow{3}{*}{ ARIMA(2,0,1) } & constant & 0.0334 & 0.0039 & 8.53 & 0.000 \\
\cline { 2 - 7 } & AR(1) & 0.1028 & 0.0648 & 1.59 & 0.116 \\
\cline { 2 - 7 } & AR(2) & 0.8862 & 0.0621 & -2019.51 & 0.000 \\
\cline { 2 - 7 } & MA(1) & -0.9876 & 0.0005 & -000 \\
\hline
\end{tabular}

\subsection{Model Diagnostic}

In addition, the model was diagnosed to see how well it fits the data. It can be seen from Fig. 2 that the $\mathrm{ACF}$ of the residuals shows that the residuals are white noise although there was a significant spike at lag 0 of the ACF which could be due to random factor. Furthermore, the plot of the Ljung-Box p-values in Fig. 2 shows that the model was adequate for representing the data as they were above the 0.05 value indicated by the blue line.
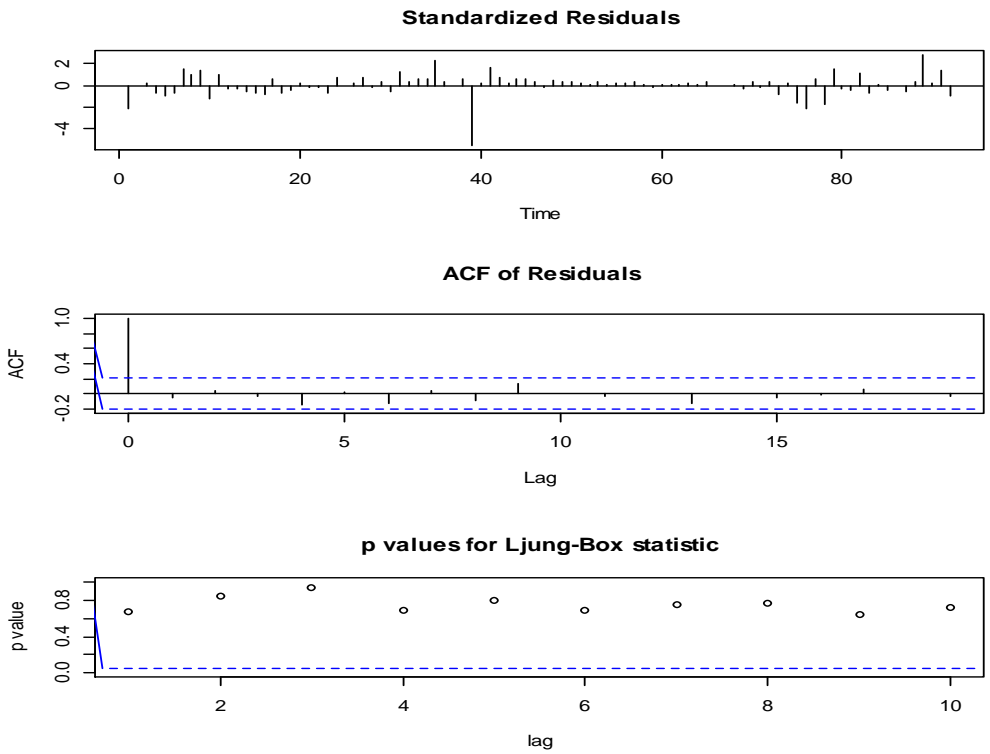

Figure 2: Diagnostic plot of residuals of $\operatorname{ARIMA}(2,0,1)$

Also, The ACF plot of Squared of Residuals, PACF plot of Squared of Residuals in Fig. 3 and an ARCH-LM test in Table 4 showed that there were no ARCH effects; hence the residuals have a constant variance. The Ljung-Box p-values (>0.05) showed that there is no serial correlation in the residuals of the model. The ACF plot of the residuals in Fig. 2 also shows that the residuals are white noise series. 
Table 4: ARCH LM Test for ARIMA(2,0,1) of residuals

\begin{tabular}{|lll|}
\hline Lag & Chi-squared & P-Value \\
\hline $\mathbf{2 4}$ & 1.7525 & 0.9997 \\
\hline $\mathbf{3 6}$ & 2.7332 & 1 \\
\hline
\end{tabular}

Squared_Residuals
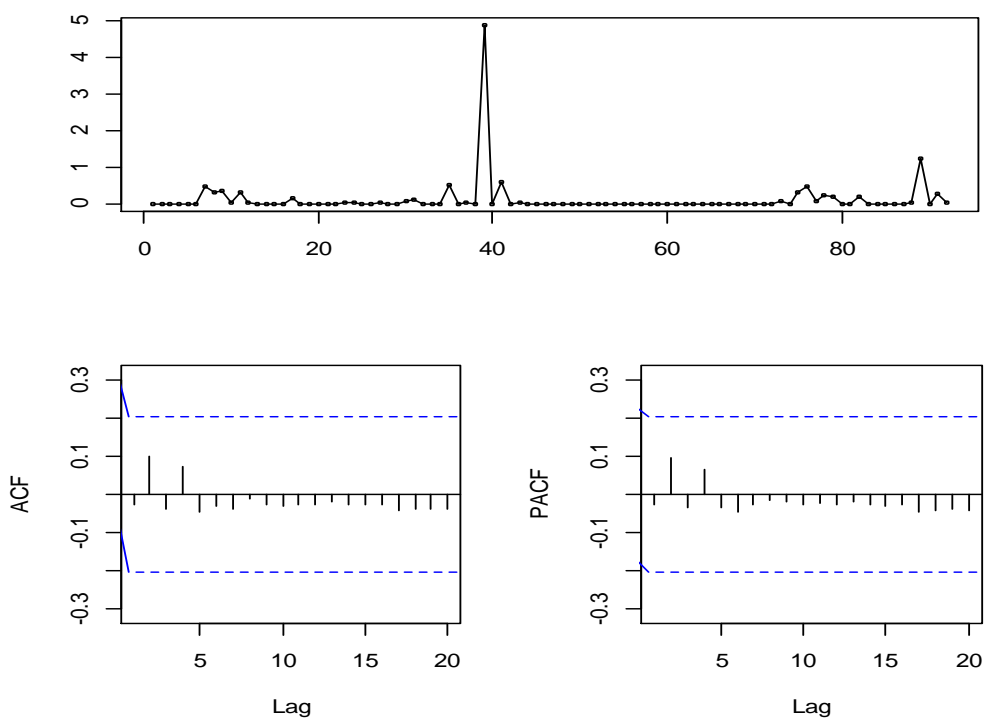

Figure 3: Diagnostic plot of squared of residuals of $\operatorname{ARIMA}(2,0,1)$

\subsection{Forecasting}

Finally, we made our forecast with the model. Since the model is adequate for prediction we believe this will impersonate the behavior of the values.

Forecasting suggest that the weekly auction results of the 91-Day Treasury Bill rates in Ghana is likely to experience a per annum interest rate between a range of $21.9849 \%$ and $23.9846 \%$. From Table 5, we can say that investors will create worth in the next eighteen (18) weeks.

Table 5: Forecast of 91-Day Treasury Bill rates from 31st March 2014 to 1st August 2014

\begin{tabular}{|c|c|c|c|c|}
\hline Weeks & Forecasts & Actual & LCL & UCL \\
\hline 31 Mar - 4 Apr & 23.2102 & 23.1698 & 22.4818 & 23.9623 \\
\hline $7 \mathrm{Apr}-11 \mathrm{Apr}$ & 23.4650 & 23.2964 & 22.3652 & 24.6189 \\
\hline $14 \mathrm{Apr}-18 \mathrm{Apr}$ & 23.6717 & 24.0693 & 22.2532 & 25.1807 \\
\hline $21 \mathrm{Apr}-25 \mathrm{Apr}$ & 23.8276 & $*$ & 22.1247 & 25.6615 \\
\hline 28 Apr - 2 May & 23.9313 & $*$ & 21.9756 & 26.0611 \\
\hline 5 May - 9 May & 23.9832 & $*$ & 21.8064 & 26.3773 \\
\hline 12 Мay - 16 May & 23.9846 & $*$ & 21.6193 & 26.6087 \\
\hline 19 Мay - 23 Мay & 23.9384 & $*$ & 21.4175 & 26.7560 \\
\hline 26 Мay - 30 May & 23.8484 & $*$ & 21.2044 & 26.8222 \\
\hline 2 Jun - 6 Jun & 23.7196 & $*$ & 20.9833 & 26.8127 \\
\hline 9 Jun - 13 Jun & 23.5571 & $*$ & 20.7573 & 26.7347 \\
\hline 16 Jun - 20 Jun & 23.3671 & $*$ & 20.5292 & 26.5975 \\
\hline 23 Jun - 27 Jun & 23.1557 & $*$ & 20.3014 & 26.4114 \\
\hline 30 Jun - 4 Jul & 22.9289 & $*$ & 20.0759 & 26.1875 \\
\hline 7 Jul - 11 Jul & 22.6930 & $*$ & 19.8544 & 25.9373 \\
\hline $14 \mathrm{Jul}-18 \mathrm{Jul}$ & 22.4535 & $*$ & 19.6384 & 25.6722 \\
\hline $21 \mathrm{Jul}$ - $25 \mathrm{Jul}$ & 22.2159 & $*$ & 19.4288 & 25.4027 \\
\hline 28 Jul - 1 Aug & 21.9849 & $*$ & 19.2268 & 25.1386 \\
\hline
\end{tabular}

*is the unknown rates in weeks that we had forecasted

\section{Conclusion}

This study was carried out to find an appropriate ARIMA model to forecast the weekly auction of government 91-Day Treasury Bill rates in Ghana. For this reason Box Jenkins methodology was used and ARIMA $(2,0,1)$ model was selected as the most suitable model based on AIC, AICC and BIC. ARIMA $(2,0,1)$ forecasting model was used to forecast the next eighteen (18) weeks of 91-Day Treasury Bill rates and it does 
not show significant volatility. From the out sample we deduce the 91-Day Treasury Bill rates in Ghana for the next eighteen (18) weeks will be between $21.9849 \%$ to $23.9849 \%$. Therefore investors can plan their future investments by considering the future behavior of the 91-Day Treasury Bill rates. On the other hand the decreasing of the interest rates of the last four (4) weeks of the eighteen (18) weeks implies an increase in the considerable demand for the government 91-Day Treasury Bill rates.

\section{References}

[1] A. Amevor, Investment: How to create wealth on the stock market (Ghana, Combert Impressions, 2005).

[2] C. Jones, A century of stock market liquidity and trading costs (Columbia University, New York, NY, 2001).

[3] D.M.K.N. Seneviratna and Mao Shuhua, Forecasting the Twelve Month Treasury Bill Rates in Sri Lanka: Box Jenkins Approach, IOSR Journal of Economics and Finance (IOSR-JEF) 1(1), 2013, 44 - 47.

[4] F. E. Brigham and F. J. Houston, Fundamentals of Financial Managemen (ninth edition, 2001).

[5] F. Okyere and C. Mensah, Empirical Modelling and Model Selection for Forecasting Monthly Inflation of Ghana. Mathematical Theory and Modeling, 4(3), 2014, 99-106.

[6] F. Reilly and K. Brown, Investments Analysis and Portfolio Management, 2003.

[7] G. Jacoby, D. Fowler and A. Gottesman, The capital asset pricing model and the liquidity effect, A theoretical approach, Journal of Financial Markets, 3, 2000, 69-81

[8] I. A. Logubayom, S. Nasiru and A. Luguterah, Modelling the Rate of Treasury Bills in Ghana, Mathematical Theory and Modeling, 3(4), 2013, 102-108.

[9] J. M. Tebbs, STAT 520 Forecasting and Time Series (University of South Carolina, Department of Statistics, spring, 2010).

[10] J.C. Paul, S. Hoque, and M.M. Rahman, Selection of Best ARIMA Model for Forecasting Average Daily Share Price Index of Pharmaceutical Companies in Bangladesh: A case Study on Square Pharmaceutical Ltd, Global Journal of Management and Business Research, 13(3), 2013.

[11] J.T. Olajide, O.A. Ayansola, M.T. Odusina, and I.F. Oyenuga, Forecasting the Inflation Rate in Nigeria: Box Jenkins Approach, IOSR Journal of Mathematics (IOSR-JM), 3(5), 2012, 15-19.

[12] L. Mahadeva and P. Robinson, Unit root testing to help model building (centre for central Bank Studies, Bank of England, 2004).

[13] M. Al-Shiab, The Predictability of the Amman Stock Exchange using the Univariate Autoregressive Integrated Moving Average (ARIMA) Model, Journal of Economic \& Administrative Sciences, 22(2), 2006.

[14] M. Brandt and K. Kavajecz, Price discovery in the U.S. Treasury Market: The impact of order flow and liquidity on the yield curve (University of Pennsylvania, Philadelphia, PA, 2002).

[15] P. Chujai, N. Kerdprasop, and K. Kerdprasop, Time Series Analysis of Household Electric Consumption with ARIMA and ARMA Models, Proc. IMECS Conf., Hong Kong, 2013.

[16] Q. Q. Aboagye, S. K. Akoena, T. O. Antwi-Asare and F. A. Gockel, Explaining Interest Rate Spreads in Ghana. African Development Review, 20(3), 2008, 378 - 399.

[17] R. G. lbbotson and Associates, Stocks, Bonds, Bills, and Inflation 1997 Yearbook (Chicago, 1997).

[18] R. Huang, J. Cai and X. Wang, Inventory risk-sharing and public information-based trading in the Treasury Note interdealer broker market (University of Notre Dame, Notre Dame, IN, 2001).

[19] R. Nochai, and T. Nochai, ARIMA Model for Forecasting Oil Palm Price, Proc. 2nd IMT-GT Regional Conf. on Mathematics, Statistics and Applications, University Sains Malaysia, Penang, 2006.

[20] S. Nasiru and S. Sarpong, Empirical Approach to Modelling and Forecasting Inflation in Ghana, Current Research Journal of Economics Theory, 4(3), 2012, 83-87.

[21] S.T. Appiah and I.A. Adetunde, Forecasting exchange rate between the Ghana cedi and the US dollar using time series analysis. Current Research Journal of Economics Theory, 3(2), 2011, 76-83. 